\title{
Treatment of Isoniazid-Resistant Pulmonary Tuberculosis
}

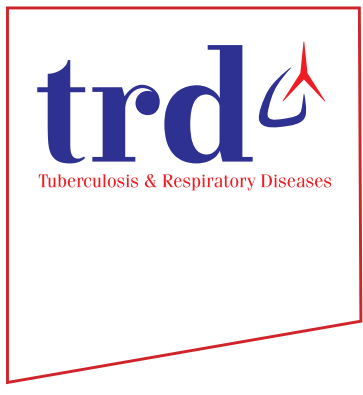

\author{
Byung Woo Jhun, M.D. ${ }^{(10)}$ and Won-Jung Koh, M.D. \\ Division of Pulmonary and Critical Care Medicine, Department of Medicine, Samsung Medical Center, Sungkyunkwan \\ University School of Medicine, Seoul, Korea
}

Tuberculosis (TB) remains a threat to public health and is the leading cause of death globally. Isoniazid (INH) is an important first-line agent for the treatment of TB considering its early bactericidal activity. Resistance to INH is now the most common type of resistance. Resistance to INH reduces the probability of treatment success and increases the risk of acquiring resistance to other first-line drugs such as rifampicin (RIF), thereby increasing the risk of multidrugresistant-TB. Studies in the 1970s and 1980s showed high success rates for INH-resistant TB cases receiving regimens comprised of first-line drugs. However, recent data have indicated that INH-resistant TB patients treated with only firstline drugs have poor outcomes. Fortunately, based on recent systematic meta-analyses, the World Health Organization published consolidated guidelines on drug-resistant TB in 2019. Their key recommendations are treatment with RIFethambutol (EMB)-pyrazinamide (PZA)-levofloxacin (LFX) for 6 months and no addition of injectable agents to the treatment regimen. The guidelines also emphasize the importance of excluding resistance to RIF before starting RIFEMB-PZA-LFX regimen. Additionally, when the diagnosis of INH-resistant TB is confirmed long after starting the first-line TB treatment, the clinician must decide whether to start a 6-month course of RIF-EMB-PZA-LFX based on the patient's condition. However, these recommendations are based on observational studies, not randomized controlled trials, and are thus conditional and based on low certainty of the effect estimates. Therefore, further work is needed to optimize the treatment of INH-resistant TB.

Keywords: Tuberculosis; Isoniazid; Resistance; Treatment

\section{Introduction}

Despite the availability of anti-tuberculosis (TB) chemotherapy, TB remains a threat to public health and is the lead-

\footnotetext{
Address for correspondence: Won-Jung Koh, M.D.

Division of Pulmonary and Critical Care Medicine, Department of

Medicine, Samsung Medical Center, Sungkyunkwan University School of Medicine, 81 Irwon-ro, Gangnam-gu, Seoul 06351, Korea

Phone: 82-2-3410-3429, Fax: 82-2-3410-3849

E-mail:wjkoh@skku.edu

Received: Aug. 28, 2019

Revised: Sep. 15, 2019

Accepted: Sep. 23, 2019

Published online: Nov. 7, 2019

(c) It is identical to the Creative Commons Attribution Non-Commercial License (http://creativecommons.org/licenses/by-nc/4.0/).
}

ing global cause of death by a single infectious agent. Approximately 10 million people worldwide develop TB annually, and 1.6 million die from the disease ${ }^{1}$. In South Korea, about 30,000 new cases of TB occur and around 2,000 people die from $\mathrm{TB}^{2,3} . \mathrm{TB}$ is a highly infectious disease in which about $30 \%$ of closely contacted people become infected and about 5\%-15\% of infected people develop TB throughout their lifetimes ${ }^{4-6}$.

Isoniazid (INH) is an important first-line anti-TB agent because of its potent early bactericidal activity. However, resistance to INH, alone or in combination with other drugs, is now the most common type of resistance to anti-TB drugs. Global data on INH resistance without concurrent rifampicin (RIF) resistance were $7.1 \%$ in new TB cases and $7.9 \%$ in previously treated TB cases ${ }^{1}$. Unfortunately, the global burden of INHresistant TB is not decreasing. A representative United States study published in 2008 reported that the prevalence of INHresistant TB had not declined, despite the downward trend in the prevalence of overall $\mathrm{TB}^{7}$. Data from the World Health Organization (WHO) showed that resistance to INH was detected in $30 \%$ of TB cases in Eastern Europe and 14\% of TB 
cases in West/Central Europe and Africa from 1994 to $2009^{8}$. National surveys and cohort studies in South Korea showed that the prevalence of INH-resistant TB over the past 20 years was approximately $10 \%$ in new cases and $>30 \%$ in previously treated cases $^{9-14}$.

The management of INH-resistant TB is important because of its unsatisfactory outcomes compared to drug-susceptible $\mathrm{TB}^{15,16}$. Previous systematic meta-analyses have shown that resistance to INH reduces the probability of treatment success and increases the risk of acquiring resistance to other important first-line drugs such as RIF, thereby increasing the risk of multidrug-resistant (MDR)-TB ${ }^{17,18}$. Moreover, INH-resistant TB generally requires longer treatment than drug-susceptible $\mathrm{TB}$, increasing the burden of the disease.

Guidance on the management of INH-resistant TB is under debate, in contrast to the consensus for the management of patients with drug-susceptible or MDR-TB. Studies performed in the 1970s and 1980s showed low rates of treatment failure for patients with INH-resistant TB receiving four or five firstline drugs in 6-month regimens ${ }^{19,20}$. However, recent data have shown that patients with INH-resistant TB who received only first-line regimens have worse outcomes than those with drug-susceptible $\mathrm{TB}^{16,18,21,22}$. Several previous international guidelines have recommended the addition of a fluoroquinolone (FQ) to strengthen anti-TB treatment regimens for INHresistant $\mathrm{TB}$, particularly for cases of extensive disease $\mathrm{e}^{23-26}$. However, little research has supported this recommendation, and no definitive randomized or controlled study has been performed. Thus, current treatment regimens for INH-resistant TB vary ${ }^{27-34}$, and the optimum regimen including use of an FQ or duration of treatment had remained controversial ${ }^{35}$. In 2019, based on comprehensive systematic meta-analyses on the management of INH-resistant $\mathrm{TB}^{22,36}$, the WHO published consolidated guidelines on drug-resistant TB, including INH-resistant $\mathrm{TB}^{37}$. Here we review studies and international guidelines on the management of INH-resistant TB.

\section{Isoniazid Resistance}

After the introduction of INH for treatment of TB in the 1950s, resistance to INH emerged ${ }^{38}$. Generally, "INH-resistant" TB refers to strain with resistance to INH and susceptibility to RIF confirmed in vitro, regardless of concurrent resistance to other anti-TB drugs. "INH mono-resistance" TB refer to resistance to a single first-line drug such as INH, and susceptibility to any other anti-TB drugs ${ }^{39}$. Resistance to INH is usually due to a mutation in $\operatorname{kat} G$ or inhA, and is less commonly due to mutations in other genes, such as the ahpC32 gene ${ }^{40,41}$. INH is a prodrug that must be activated by catalase-peroxidase, an enzyme regulated by $k a t G$, to be effective against TB. Mutations in $k a t G$, most commonly at Ser315Thr, can result in highlevel resistance to $\mathrm{INH}^{42,43}$. The $i n h A$ gene encodes an enoyl acyl carrier protein reductase involved in fatty acid synthesis in M. tuberculosis. Because these fatty acids are the targeted by the active derivative of INH, mutations in inhA or its promoter region block INH binding and result in low-level INH resistance $^{44}$. Isolates with an inhA mutation are also typically resistant to ethionamide and prothionamide ${ }^{45}$.

In Mycobacterium tuberculosis, drug resistance develops through spontaneous genetic mutations. Thus, the development of acquired drug resistance usually occurs when there is a large bacterial population, such as in pulmonary cavities ${ }^{46}$ or when an inadequate drug combination or dosage is prescribed $^{15,47}$. Rarely, malabsorption of anti-TB drugs may account for acquired resistance ${ }^{48}$. Risk factors for developing INH resistance have been reported, and most studies have found a strong correlation between a history of TB treatment and INH resistance. In an analysis of drug-resistant TB trends in the United States, a history of TB, foreign birth, and Asian or Pacific Islander ethnicity were found to be risk factors for INH resistance $^{29,49}$. Similarly, in Germany and Israel, a history of TB treatment was identified as a risk factor for INH resistance ${ }^{50,51}$.

\section{Burden of Isoniazid Resistant TB in South Korea}

The prevalence of drug-resistant TB is used as a surrogate marker for the performance of national tuberculosis control programs. INH resistance could serve as an indicator of drug resistance to TB because INH is inevitably used in the initial treatment regimens. From the 1960s to the 1990s, nationwide TB prevalence surveys were conducted in South Korea, and initial and acquired resistance to anti-TB drugs in patients with culture-confirmed TB were enumerated (Table 1) ${ }^{9-11}$. In the surveys, the prevalence of INH resistance was found to have increased significantly from $25 \%$ in 1965 to $44 \%$ in 1980 , and decreased markedly thereafter to $22 \%$ in $1990^{\circ}$. From the 1990s to 2004, a further four surveys of TB patients registered for treatment at health centers were conducted in South Korea $(\text { Table } 1)^{12}$. During the survey period, the prevalence of drugresistant TB decreased markedly due to improved treatment efficacy. However, since 1994, the incidence of INH resistance has increased in new cases and decreased in retreatment cases.

The rates of resistance to anti-TB drugs in six university hospitals in South Korea in 2010 have been reported ${ }^{13}$. Among 542 M. tuberculosis isolates from patients with pulmonary TB, including $473(87 \%)$ from new cases and 69 (13\%) from previously treated cases, the rates of INH resistance were approximately $14 \%$. Recently, a study was conducted to evaluate the drug-resistance rates of 5,599 clinical M. tuberculosis isolates collected from 2010 to 2014 at seven tertiary hospitals in South Korea ${ }^{14}$. In that study, 4,927 (88\%) were from new cases and $672(12 \%)$ were from previously treated cases, with INH 
Table 1. Prevalence of isoniazid resistance in patients with tuberculosis in South Korea ${ }^{9-12}$

\begin{tabular}{|lcccccccccc|}
\hline & \multicolumn{7}{c|}{ Year of survey } \\
\cline { 2 - 10 } & $\mathbf{1 9 6 5}$ & $\mathbf{1 9 7 0}$ & $\mathbf{1 9 7 5}$ & $\mathbf{1 9 8 0}$ & $\mathbf{1 9 8 5}$ & $\mathbf{1 9 9 0}$ & $\mathbf{1 9 9 4}$ & $\mathbf{1 9 9 9}$ & $\mathbf{2 0 0 3}$ & $\mathbf{2 0 0 4}$ \\
\hline Total tested cases & $71(100)$ & $132(100)$ & $270(100)$ & $177(100)$ & $247(100)$ & $189(100)$ & - & - & - \\
\hline Any INH resistance & $18(25)$ & $46(35)$ & $93(34)$ & $77(44)$ & $63(26)$ & $42(22)$ & - & - & - \\
\hline New cases & $42(100)$ & $92(100)$ & $189(100)$ & $108(100)$ & $161(100)$ & $127(100)$ & 2,486 & 2,370 & 1,348 & 2,636 \\
& & & & & & & $(100)$ & $(100)$ & $(100)$ & $(100)$ \\
Any INH resistance & $7(17)$ & $18(20)$ & $34(18)$ & $27(25)$ & $22(14)$ & $16(13)$ & $192(8)$ & $204(9)$ & $134(10)$ & $261(10)$ \\
\hline INH-mono-resistance & - & - & - & - & - & - & $97(4)$ & $109(5)$ & $64(5)$ & $133(5)$ \\
Previously treated cases & $29(100)$ & $40(100)$ & $81(100)$ & $69(100)$ & $86(100)$ & $62(100)$ & $189(100)$ & $283(100)$ & $622(100)$ & $278(100)$ \\
\hline Any INH resistance & $11(38)$ & $28(70)$ & $59(73)$ & $50(73)$ & $41(48)$ & $26(42)$ & $86(46)$ & $49(17)$ & $154(25)$ & $67(24)$ \\
INH-mono-resistance & - & - & - & - & - & - & $17(9)$ & $18(6)$ & $50(8)$ & $19(7)$ \\
\hline
\end{tabular}

Values are presented as number (\%).

INH: isoniazid.

resistance rates of $11 \%$ and $35 \%$, respectively. Therefore, the burden of INH-resistant TB in South Korea is still considerable.

\section{Previous Studies on the Treatment Outcomes of Isoniazid-Resistant TB}

\section{Ineffectiveness of first-line drug regimens for isoniazid-resistant tuberculosis}

No definitive randomized or controlled studies have been performed to date that have determined the optimal treatment regimen for patients with INH-resistant TB. Thus, in this chapter, we describe key studies on the management of INHresistant TB. A number of clinical trials conducted by the British Medical Research Council in the 1970s and 1980s showed that patients with INH-resistant TB responded well to 6-month chemotherapy regimens that included RIF and pyrazinamide (PZA) with treatment success rates above $95 \%{ }^{19}$. Based on these data, in 1994 the American Thoracic Society (ATS) and the Centers for Disease Control and Prevention (CDC) recommended a 6-month treatment regimen for INH-resistant $\mathrm{TB}^{52}$. Patients with INH-resistant TB were recommended to receive RIF, ethambutol (EMB), and PZA for 6 months. Several subsequent international guidelines also recommended combination regimens of first-line anti-TB drugs for INH-resistant $\mathrm{TB}^{53-55}$, supported by the results of several studies ${ }^{27,29,56-60}$.

However, since the late 1990s to early 2000s, several studies yielded results that conflicted with those of the above studies (Table 2). The use of only first-line anti-TB drugs for INH-resistant TB occasionally resulted in poor outcomes. Moreover, the acquisition of additional drug resistance upon treatment failure was a concern. In a controlled trial in 1997 in India comparing three short-course regimens of first-line
anti-TB drugs, an unfavorable response and relapse occurred in $17 \%-62 \%$ and $8 \%-25 \%$ of 227 patients with INH-resistant TB, respectively ${ }^{61}$. Notably, among 74 patients with INHresistant TB who had an unfavorable response, 23 (31\%) had acquired resistance to RIF. In 2000, the outcomes of standard short-course therapy for drug-resistant TB in Dominica, Hong Kong, Italy, Russia, South Korea, and Peru were published ${ }^{16}$. Of 457 INH-resistant TB patients, 82 (18\%) had unfavorable outcomes, including failure (2\%), death (4\%), default $(6 \%)$, and transfer (6\%), suggesting that INH resistance is associated with unfavorable outcomes of treatment with first-line regimens $^{16}$. In a 2004 Russian retrospective study that included 180 patients with INH-resistant TB, but not MDR-TB, who received the WHO standardized short-course or retreatment regimen, the unfavorable outcome rate was $30 \%$, comprised of 17 (9\%) deaths, $21(12 \%)$ treatment failures, 11 defaults (6\%), and five transfer $(3 \%)^{62}$. Similarly, in a large study in Georgia including $889 \mathrm{INH}$ resistant TB patients treated for 9 months with RIF-EMB-PZA, 135 (15\%) had unfavorable treatment outcomes $^{21}$. In addition, studies in Israel ${ }^{51}$, Taiwan ${ }^{63}$, Mexico ${ }^{64}$, and India ${ }^{65}$ reported unfavorable outcome rates of $7 \%-44 \%$ among patients with INH-resistant TB treated with first-line drugs. Therefore, patients with INH-resistant TB could have worse outcomes, even when treated with a first-line regimen or the WHO-retreatment regimen. These findings are probably because previous studies may not adequately reflect the clinical characteristics in a real-world population of patients with many underlying diseases. These data suggest the need for a more effective regimen for patients with INH-resistant TB.

\section{Acquisition of resistance to additional drugs}

Acquisition of additional drug resistance, especially for RIF, is an important concern during the treatment of INH-resistant 
Table 2. Treatment outcomes of patients with isoniazid-resistant tuberculosis in previous studies

\begin{tabular}{|c|c|c|c|c|c|c|}
\hline Study & Study type & Regimen & $\begin{array}{c}\text { No. of } \\
\text { patients }\end{array}$ & $\begin{array}{l}\text { Unfavorable } \\
\text { response }\end{array}$ & Relapse & $\begin{array}{c}\text { Acquired resistance } \\
\text { to } R \text { in unfavorable } \\
\text { response }\end{array}$ \\
\hline \multirow[t]{3}{*}{ Narayanan $(1997)^{61}$} & $\begin{array}{l}\text { Prospective } \\
\text { controlled }\end{array}$ & 2HREZ/6HE & 94 & $16(17)^{*}$ & $6(8)$ & $3 / 16$ \\
\hline & & $2 \mathrm{HREZ}_{2} / 4 \mathrm{HRE}_{2}$ & 59 & $12(20)^{*}$ & $11(25)$ & $7 / 12$ \\
\hline & & $2 \mathrm{HRZ}_{2} / 4 \mathrm{HR}_{2}$ & 74 & $46(62)^{*}$ & $4(15)$ & $13 / 46$ \\
\hline $\begin{array}{l}\text { Espinal et al. } \\
(2000)^{16}\end{array}$ & Retrospective & 2HREZ(S)/4HR & 457 & $82(18)^{\dagger}$ & - & - \\
\hline Narayanan $(2001)^{67}$ & Retrospective & $\begin{array}{l}\text { 2HREZ/6HE, } 2 \mathrm{HREZ}_{2} / 4 \mathrm{HRE}_{2} \text {, } \\
\text { 2HREZ }_{3} / 4 \mathrm{HR}_{2} \\
\text { 3HREZ }_{3} / 3 \mathrm{HR}_{2}\end{array}$ & 320 & $60(19)^{*}$ & $41(13)$ & $32 / 60$ \\
\hline Seung et al. $(2004)^{62}$ & Retrospective & 2HREZ(S)/4HR & 180 & $54(30)^{\dagger}$ & - & - \\
\hline Koh et al. $(2005)^{66}$ & Case report & 2HREZ/10RE & 1 & 1 & - & 1 \\
\hline \multirow{3}{*}{ Kim et al. $(2008)^{28}$} & Retrospective & 2HREZ/10RE & 21 & $2^{*}$ & - & $2 / 2$ \\
\hline & & 2HREZ/7RE & 5 & - & - & - \\
\hline & & 2HREZ/4REZ & 13 & $1^{*}$ & - & - \\
\hline Bang et al. $(2010)^{30}$ & Retrospective & 8(H)REZ or REZ(FQ) $)^{\S /}$ & 110 & $22(20)^{\dagger}$ & - & - \\
\hline Fox et al. $(2011)^{51}$ & Retrospective & 10HREZ & 38 & $2(7)^{\ddagger}$ & - & - \\
\hline $\begin{array}{l}\text { Jacobson et al. } \\
(2011)^{68}\end{array}$ & Retrospective & 12HREZ(S) & 155 & $25(16)^{*}$ & - & $14 / 23$ \\
\hline Gegia et al. $(2012)^{21}$ & Retrospective & 9REZ & 889 & $135(15)^{\dagger}$ & - & - \\
\hline Deepa et al. $(2013)^{65}$ & Retrospective & $2 \mathrm{HREZS}_{3} / 1 \mathrm{HREZ}_{3} / 5 \mathrm{HRE}_{3}$ & 144 & $64(44)^{\dagger}$ & - & - \\
\hline Wang et al. $(2014)^{63}$ & Retrospective & $\begin{array}{l}\text { 2HREZ/4-10REZ or 10RE or } \\
\text { 10RZ }\end{array}$ & 114 & $20(18)^{\dagger}$ & - & - \\
\hline Chien et al. $(2015)^{70}$ & Retrospective & 2HREZ/4HR(FQ) & 395 & $67(17)^{*}$ & - & - \\
\hline \multirow[t]{2}{*}{ Lee et al. $(2016)^{69}$} & Retrospective & 6-9REZ & 65 & $6(9)^{\ddagger}$ & $4 / 59(7)$ & - \\
\hline & & 6-9REZ FQ & 75 & $1(1)^{\dagger}$ & $1 / 74(1)$ & \\
\hline $\begin{array}{l}\text { Baez-Saldana et al. } \\
(2016)^{64}\end{array}$ & $\begin{array}{l}\text { Prospective } \\
\text { observational }\end{array}$ & $\begin{array}{l}\text { 2HREZ/4HR or } \\
\text { 2HREZS/1HREZ/5HRE }\end{array}$ & 88 & $22(25)^{\dagger}$ & $9 / 80(11)$ & - \\
\hline $\begin{array}{l}\text { Villegas et al. } \\
(2016)^{71}\end{array}$ & $\begin{array}{l}\text { Prospective } \\
\text { observational }\end{array}$ & $\begin{array}{l}\text { 2HREZ/4HR or } 7-12 \mathrm{HREZ} \text { or } \\
\text { 7-12(H)REZ(L) }\end{array}$ & 85 & $22(26)^{\dagger}$ & - & - \\
\hline $\begin{array}{l}\text { Romanowski et al. } \\
(2017)^{32}\end{array}$ & Retrospective & $\begin{array}{l}\text { 6-12 or } 12>(\mathrm{H}) \mathrm{REZ} /(\mathrm{H}) \\
\text { RE(FQ) }\end{array}$ & 165 & $8(5)^{*}$ & $4(2)$ & - \\
\hline $\begin{array}{l}\text { Cornejo Garcia et al. } \\
(2018)^{72}\end{array}$ & Retrospective & 9REZL(injectable AG) & 947 & $216(23)^{\dagger}$ & - & - \\
\hline
\end{tabular}

Values are presented as number (\%).

*Data included death and treatment failure. 'Data included death, treatment failure, default, and transfer. "Data included only treatment fail-

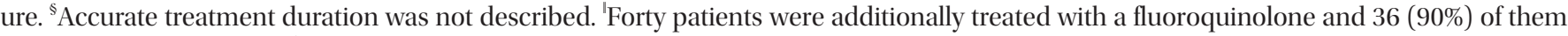
were treated successfully. 'One hundred and two were additionally treated with a fluoroquinolone.

Subscripts for anti-tuberculosis drug abbreviations; 2: twice weekly; 3: thrice weekly. The absence of a subscript for anti-tuberculosis means daily therapy.

H: isoniazid; R: rifampicin; E: ethambutol; Z: pyrazinamide; FQ: fluoroquinolone; L: levofloxacin; AG: aminoglycoside.

TB using first-line regimens, and can lead to the emergence of MDR-TB. Studies on the acquisition of drug resistance have steadily been reported, especially among patients who had unfavorable outcomes after treatment of INH-resistant TB.
For example, in a report from South Korea, a patient with INHresistant TB acquired MDR during 12 months of treatment with RIF-EMB, with PZA administered during the initial 2 months ${ }^{66}$. The authors subsequently reported the outcomes 
of 39 patients with INH-resistant TB who were treated with first-line anti-TB drug regimens ${ }^{28}$. Treatment failure occurred in three (8\%), and MDR was identified in two of the three patients during treatment for 2 months with INH-RIF-EMB-PZA and 10 months of RIF-EMB treatment. In an Indian study of 1,817 patients with TB, although resistance to RIF emerged in only $2 \%$ of the patients, 32 of 60 patients (53\%) with INH-resistant TB who had unfavorable outcomes acquired resistance to $\mathrm{RIF}^{67}$. A 2011 South African study evaluated the outcomes of a retrospective cohort of 155 patients with INH-resistant TB who received the standard first-line four-drug therapy for 1 year $^{68}$. In that study, 14 of 23 patients $(61 \%)$ whose therapy failed progressed to MDR-TB, although the retreatment cases also received streptomycin (SM) for the first 2.5-3.5 months.

\section{Use of FQs for isoniazid-resistant TB}

Former WHO and United States guidelines recommended the addition of an FQ to strengthen anti-TB regimens for INHresistant TB, especially for patients with extensive disease $\mathrm{e}^{23-26}$. Although little clinical evidence initially supported this recommendation, recent studies have verified the benefit of addition of an $\mathrm{FQ}^{30,69-71}$. In a Danish study in 2002-2007, 40 of 110 patients (36\%) with INH-resistant TB were additionally treated with an FQ, resulting in treatment success in $36(90 \%)^{30}$. In a retrospective study in South Korea of 140 patients with INHresistant $\mathrm{TB}$, treatment failure was more frequent among the patients who did not receive FQs than those who did (6/65, 9\% vs. $1 / 75,1 \% ; \mathrm{p}=0.049)^{69}$.

Similarly, in a Taiwanese study of 395 patients with INHresistant $\mathrm{TB}$, supplementation with an FQ significantly improved the treatment success rate $(60 \% \text { vs. } 13 \%, \mathrm{p}=0.003)^{70}$. In a retrospective study in Canada, 12 of 165 patients (7\%) with INH-resistant TB had an unfavorable outcome of treatment with first-line drugs with or without addition of a $\mathrm{FQ}^{32}$. Interestingly, no relapse occurred in the 61 patients (37\%) who received an FQ-containing regimen. Additionally, in a large retrospective study in Peru, the treatment outcomes of 947 patients with INH-resistant TB who were treated with a standardized 9-month regimen of RIF-EMB-PZA plus levofloxacin (LFX) were evaluated ${ }^{72}$. In that study, death and treatment failure occurred in only $18(2 \%)$ and 12 cases (1\%), respectively, although 186 cases $(20 \%)$ were lost to follow-up. These data suggest that the addition of an FQ may enhance the treatment of INH-resistant TB.

\section{Systematic reviews and meta-analyses of isoniazid- resistant $\mathrm{TB}$}

Several recent meta-analyses of INH-resistant TB have indicated the limited efficacy of regimens consisting of only firstline anti-TB agents against INH-resistant TB. In 2009, Menzies et al. ${ }^{18}$ analyzed whether standardized first-line drugs or WHO retreatment regimens are appropriate for patients with INHresistant TB or retreatment cases. Interestingly, among the six cohort studies included in that meta-analysis, the treatment failure rates were $18 \%-44 \%$ for INH-resistant TB. Thus, given that the WHO regimen was designed for resource-poor settings with a low initial prevalence of drug resistance, standardized empirical treatment without drug susceptibility testing could be contributing to MDR, particularly when there is a high prevalence of INH resistance.

Gegia et al. ${ }^{22}$ performed a meta-analysis that included 3,744 patients with INH-resistant TB and 19,012 with INH-susceptible TB from nine cohort studies and 33 trials. Treatment of INH-resistant TB with the WHO standardized regimen for new patients ( 2 months of INH-RIF-EMB-PZA followed by 4 months of INH-RIF) resulted in treatment failure, relapse, and MDR in $11 \%, 10 \%$, and $8 \%$, respectively, of the patients. While the rates for patients with drug-susceptible TB who received the standard retreatment regimen were $1 \%, 5 \%$, and $0.3 \%$, respectively. More importantly, among the patients with initial INH-resistant TB who acquired drug resistance, 96\% (205/214) acquired MDR. Finally, overall failure, relapse, and acquired drug resistance were more common in patients with INH-resistant TB than those with drug-susceptible TB treated with standardized regimens of first-line drugs.

In 2018, Fregonese et al. ${ }^{36}$ evaluated the optimal duration and combination of anti-TB drugs for INH-resistant TB among 3,923 patients with INH-resistant TB from 23 cohort studies. Compared with a daily regimen of 6 months of RIF-EMB-PZA, extending the duration to 8-9 months had similar outcomes. Another notable finding was that the addition of an FQ to 6 months or more of RIF-EMB-PZA was associated with a significantly greater treatment success rate (adjusted odds ratio $[\mathrm{aOR}], 2.8 ; 95 \%$ confidence interval [CI], 1.1-7.3), but had no statistically significant impact on mortality or the acquisition of RIF resistance. Also, the use of an FQ plus 1-3 months of PZA (6 months of RIF-EMB and 1-3 months of PZA plus FQ) was more likely to be associated with treatment success than a 6-month RIF-EMB-PZA regimen. However, the small number of patients limited the statistical power. Interestingly, addition of SM during the initial months of treatment was associated with worse outcomes in patients with INH-resistant TB.

\section{International Guidelines for the Management of Isoniazid Resistant TB}

The recommended regimens for INH-resistant TB differ among countries and have differed over time. In this chapter, we summarize previous and current international guidelines for the treatment of INH-resistant TB (Table 3). 
Table 3. International guidelines for isoniazid-resistance tuberculosis treatment

\begin{tabular}{|c|c|c|}
\hline Guideline & Suggested regimen & Duration (mo) \\
\hline \multirow[t]{2}{*}{ ATS/CDC (1994) } & REZ & 6 \\
\hline & $\mathrm{RE}$ & 12 \\
\hline ATS/CDC (2003) & REZ (FQ for extensive disease) & 6 \\
\hline \multirow[t]{2}{*}{ BTS (1998) } & 2SREZ/7RE & 9 \\
\hline & 2REZ/10RE & 12 \\
\hline \multirow[t]{2}{*}{ NICE (2011) } & 2SREZ/7RE & 9 \\
\hline & 2REZ/10RE & 12 \\
\hline NICE, 2016 & 2(H)REZ/7RE (10 months for extensive disease) & $9-12$ \\
\hline \multirow[t]{3}{*}{ Canadian Tuberculosis Standards (2014) } & 2(H)RZE/4-7REZ & $6-9$ \\
\hline & 2(H)RZE/10RE & 12 \\
\hline & 2(H)RZEQ/4-7RE FQ & $6-9$ \\
\hline WHO (2006) & REZ $(F Q)^{*}$ & $6-9$ \\
\hline WHO (2008) & REZ (FQ)* & $6-9$ \\
\hline WHO (2014) & $\mathrm{REZ}(\mathrm{FQ})^{*^{\dagger}}$ & $6-9$ \\
\hline WHO (2018) & REZ FQ $(\mathrm{L}>\mathrm{M})^{\dagger}$ & 6 \\
\hline
\end{tabular}

*A fluoroquinolone may strengthen the regimen for patients with extensive disease. 'Use Xpert MTB/RIF at month 0, 2, and 3 and if rifampicin resistance is found switch to full multidrug resistant-tuberculosis treatment. ${ }^{*}$ The new 2018 World Health Organization guidelines recommend levofloxacin as the first choice, rather than moxifloxacin.

ATS: American Thoracic Society; CDC: Centers for Disease Control and Prevention; BTS: British Thoracic Society; NICE: National Institute for Health and Care Excellence; WHO: World Health Organization; H: isoniazid; R: rifampicin; E: ethambutol; Z: pyrazinamide; FQ: fluoroquinolone; L: levofloxacin; M: moxifloxacin.

\section{United States}

The ATS and CDC published guidelines in $1994^{52}$. These guidelines stated that INH should be discontinued upon diagnosis of INH-resistant TB. Additionally, these guidelines recommended (1) 6 months of daily RIF-EMB-PZA if PZA was included in the initial regimen or (2) 12 months of daily RIFEMB if PZA was not included. Subsequently, revised guidelines published in 2003 recommended 6 months of RIF-EMBPZA for INH-resistant TB and added that an FQ may enhance the regimen for patients with extensive disease ${ }^{23}$.

\section{United Kingdom}

In 1998 the British Thoracic Society recommended a regimen for INH-resistant $\mathrm{TB}^{53}$. If INH resistance had been identified before starting treatment, a regimen of 2 months of SM-RIF-EMB-PZA followed by 7 months of RIF-EMB was recommended. However, if INH resistance was identified after treatment initiation, they recommended that INH treatment be discontinued and replaced by 12 months of RIF-EMB treatment.

The 2011, National Institute for Health and Care Excellence (NICE) guidelines recommended the same regimen as the 1998 British Thoracic Society guideline ${ }^{54}$. However, in the 2016 revised NICE guidelines, 2 months of RIF-EMB-PZA $( \pm \mathrm{INH})$ followed by 7 months of RIF-EMB was recommended. In cases of extensive disease, the continuation phase could be extended to 10 months ${ }^{55}$.

\section{Canadian Tuberculosis Standards}

The 2014 Canadian Tuberculosis Standards recommended that patients suspected of having INH-resistant TB should be treated with all four first-line drugs while the result of drug susceptibility testing is pending ${ }^{73}$. INH could be discontinued upon identification of INH resistance, but INH could be continued if the level of resistance is low. Notably, the guidelines stated that an FQ would be equally efficacious ${ }^{74}$ and an FQ is interchangeable with INH for the treatment of INH-resistant TB. Thus, the guidelines recommended three regimens: (1) 2 months of daily RIF-EMB-PZA $( \pm$ INH) followed by $4-7$ months of daily RIF-EMB- PZA $^{20}$ or (2) followed by 10 months of daily RIF-EMB, or (3) 2 months of daily RIF-EMB-PZA-FQ $( \pm$ INH) followed by 4-7 months of daily RIF-EMB-FQ.

\section{Previous WHO guidelines for the management of isoniazid-resistant TB}

The 2006 and 2008 WHO guidelines stated that if INH mo- 
no-resistance is known or suspected at the time of treatment initiation, the addition of EMB to INH, RIF, and PZA in the intensive phase is recommended; and RIF-EMB-PZA can be administered for 6-9 months in the continuation phase. The guidelines also stated that for patients with more extensive disease, the addition of an FQ and prolongation of treatment to a minimum of 9 months can be considered ${ }^{25,26}$.

The 2014 WHO guidelines recommended the same regimens for INH-resistant $\mathrm{TB}^{24}$. However, the $2014 \mathrm{WHO}$ guidelines emphasized the need for monitoring acquisition of resistance to RIF when the RIF-EMB-PZA regimen is used to treat mono-INH-resistant TB. Because susceptibility testing to EMB and PZA is not considered reliable, infection with an INH mono-resistant strain, and not a poly-resistant strain, can be unclear at the start of treatment ${ }^{24}$. Thus, the guidelines recommended that patients not responding clinically and remaining smear- or culture-positive after 2-3 months should be tested using the Xpert MTB/RIF assay to determine RIF resistance; an MDR-TB regimen should be adopted if RIF resistance is detected. Thus, the WHO recommended use of the Xpert MTB/ RIF at months 0,2 , and 3 .

\section{New WHO guidelines for isoniazid-resistant TB}

Based on the most recent meta-analyses on the management of INH-resistant $\mathrm{TB}^{18,22,36}$, the WHO in 2018 issued evidence-based policy recommendations for the treatment of patients with INH-resistant $\mathrm{TB}^{39}$. In 2019, the WHO formally published "consolidated guidelines on drug-resistant TB treatment" ${ }^{\prime 37}$. The key recommendations for treatment of INHresistant and RIF-susceptible TB are (1) treatment with RIFEMB-PZA-LFX for 6 months and (2) no addition of SM or other injectable agents to the treatment regimen.

The most notable aspect of these guidelines is that an FQ, preferably LFX, should be included in the treatment regimen for INH-resistant TB. The new guidelines, which are based primarily on individual patient data or observational studies conducted in various settings ${ }^{32,36}$, indicate that supplementation with an FQ may enhance the efficacy of treatment regimens for INH-resistant TB. The evidence review of the guidelines emphasized that the treatment success rate was higher when an FQ was added to RIF-EMB-PZA regimens compared to $\geq 6$ months of RIF-EMB-PZA (aOR, 2.8; 95\% CI, 1.1-7.3). The addition of an FQ to a 6-month RIF-EMB-PZA regimen tended to reduce the number of deaths (aOR, 0.4; 95\% CI, 0.2-1.1) and the acquisition of RIF resistance (aOR, 0.10; 95\% CI, 0.01-1.2).

Regarding selection of an FQ, interestingly, the new WHO guidelines recommend LFX as the first choice rather than moxifloxacin. This is because LFX has a better safety profile than other FQs and was frequently used in the studies reviewed. Also, LFX has fewer drug interactions than moxifloxacin; in particular, LFX is less affected by RIF. For example, the plasma peak concentration of LFX is not affected by the addi- tion of $\mathrm{RIF}^{75,76}$. Additionally, there are no contraindications for the use of LFX with antiretroviral agents, which is important for patients infected with human immunodeficiency virus. However, LFX has contraindications: (1) cases in which resistance to RIF cannot be excluded, (2) known or suspected resistance to LFX, (3) known intolerance to FQ, (4) known or suspected risk for a prolonged QTc interval, and (5) pregnancy or breastfeeding (not an absolute contraindication). Thus, if an FQ cannot be used, patients with INH-resistant TB may be treated with RIF-EMB-PZA for 6 months.

The duration of treatment for INH-resistant TB is specified as not more than 6 months in the new WHO guidelines. Regarding the total treatment duration, a previous meta-analysis demonstrated that a 6 month RIF-EMB-PZA regimen had a higher likelihood of treatment success than a regimen of $>6$ months ${ }^{36}$. However, there is a risk of hepatotoxicity with the newly recommended regimen for INH-resistant TB due to the long-term use of PZA and RIF simultaneously. Drug-induced hepatotoxicity is not uncommon with anti-TB drugs, particularly with the prolonged use of PZA, which was demonstrated in patients on RIF and PZA for latent TB infection ${ }^{77}$. Thus, the patients in whom PZA treatment can be maintained for long periods are difficult to identify. A previous meta-analysis showed that, when PZA is discontinued due to adverse effects, a reduction in the duration of treatment with PZA to less than 3 months can result in worse outcomes, even with the addition of $\mathrm{SM}^{36}$. However, the optimum duration of treatment with PZA is unclear.

In the new WHO guidelines, the addition of SM or other injectable agents to the treatment regimen is not recommended. This is primarily based on a recent meta-analysis that showed that the addition of SM ( $\leq 3$ months) to a RIF-EMB-PZA regimen with $<4$ months of PZA treatment decreased the likelihood of treatment success ${ }^{36}$, although an effect that may in part be due to confounding. Additionally, the addition of SM did not reduce the mortality rate significantly. Also, there was no clear evidence that the addition of INH benefits or harms patients. Although the data on the use of high-dose INH were insufficient, in vitro evidence suggests that in the presence of inhA mutations but not kat $G$ mutations, increasing the dose of INH is likely to be effective. However, in the presence of $k a t G$ mutations, which typically confer higher-level resistance, the use of even high-dose INH is less likely to be effective ${ }^{78}$.

Therefore, in clinical practice, several points should be considered when treating INH-resistant TB. First, before starting the RIF-EMB-PZA-LFX regimen, resistance to RIF must be excluded by genotypic or phenotypic methods. Preferably, resistance to FQ, and if possible to PZA, should be excluded prior to treatment to prevent the acquisition of resistance to other drugs. Empirical treatment of INH-resistant TB is generally not advised, but in cases in which INH-resistant TB is strongly suspected (e.g., close contacts of patients with active TB but without laboratory confirmation of INH resistance), the RIF- 
EMB-PZA-LFX regimen may be introduced pending laboratory confirmation of INH resistance if RIF resistance has been reliably excluded.

Second, in patients in whom INH-resistant TB is confirmed after treatment with the standardized regimen (2 months of INH-RIF-EMB-PZA followed by 4 months of INH-RIF), the RIF-EMB-PZA component drugs should be continued and LFX should be added when RIF resistance has been excluded. The duration of a RIF-EMB-PZA LFX regimen is usually determined by the need for 6 months of LFX treatment. Thus, in cases in which INH-resistant TB is diagnosed after initiation of first-line TB treatment, the patient may undergo at least 6 months of drugs by the end of treatment. When INH resistance is confirmed late during the standardized regimen, the clinician must decide, based on the patient's condition, whether a 6-month course of RIF-EMB-PZA-LFX should be started at that point.

\section{Conclusion}

INH is an important first-line agent for the treatment of TB due to its potent early bactericidal activity. Resistance to INH is now the most common type of TB resistance. Studies in the 1970s and 1980s found a low rate of treatment failure for INH-resistant TB cases receiving 6-month regimens comprising four or five first-line drugs; however, recent studies have shown that INH-resistant TB patients treated with only firstline drugs have poor outcomes. Based on recent comprehensive systematic meta-analyses, the WHO published new consolidated guidelines on drug-resistant TB in 2019. Their key recommendations are (1) treatment with RIF-EMB-PZALFX for 6 months and (2) no addition of SM or other injectable agents to the treatment regimen. Thus, the guidance emphasizes the importance of excluding resistance to RIF before starting RIF-EMB-PZA-LFX treatment of INH-resistant TB. Additionally, when the diagnosis of INH-resistant TB is confirmed, long after starting first-line TB treatment, the clinician must decide whether to start a 6 month course of RIFEMB-PZA-LFX, based on the patient's condition. However, these recommendations are based on observational studies, not randomized controlled trials, and are thus conditional and based on low certainty in the estimates of effect. Therefore, further work is needed to optimize the treatment of INHresistant $\mathrm{TB}$.

\section{Authors' Contributions}

Conceptualization: Jhun BW, Koh WJ. Writing - original draft preparation: Jhun BW, Koh WJ. Approval of final manuscript: all authors.

\section{Conflicts of Interest}

Dr. Won-Jung Koh served on Advisory Boards for Johnson and Johnson and Insmed, not associated with the submitted work. Dr. Byung Woo Jhun has no conflicts of interest.

\section{Funding}

No funding to declare.

\section{References}

1. World Health Organization. Global tuberculosis report 2018 [Internet]. Geneva: World Health Organization; 2018 [cited 2018 Dec 18]. Available from: https://www.who.int/tb/publications/global_report/en/.

2. Cho KS. Tuberculosis control in the Republic of Korea. Epidemiol Health 2018;40:e2018036.

3. Kim JH, Yim JJ. Achievements in and challenges of tuberculosis control in South Korea. Emerg Infect Dis 2015;21:1913-20.

4. Getahun H, Matteelli A, Chaisson RE, Raviglione M. Latent Mycobacterium tuberculosis infection. N Engl J Med 2015;372:2127-35.

5. Pai M, Behr MA, Dowdy D, Dheda K, Divangahi M, Boehme CC, et al. Tuberculosis. Nat Rev Dis Primers 2016;2:16076.

6. Lee SH. Tuberculosis infection and latent tuberculosis. Tuberc Respir Dis 2016;79:201-6.

7. Hoopes AJ, Kammerer JS, Harrington TA, Ijaz K, Armstrong LR. Isoniazid-monoresistant tuberculosis in the United States, 1993 to 2003. Arch Intern Med 2008;168:1984-92.

8. Jenkins HE, Zignol M, Cohen T. Quantifying the burden and trends of isoniazid resistant tuberculosis, 1994-2009. PLoS One 2011;6:e22927.

9. Kim SJ, Bai GH, Hong YP. Drug-resistant tuberculosis in Korea, 1994. Int J Tuberc Lung Dis 1997;1:302-8.

10. Kim SJ, Hong YP. Drug resistance of Mycobacterium tuberculosis in Korea. Tuber Lung Dis 1992;73:219-24.

11. Hong YP, Kim SJ, Kwon DW, Chang SC, Lew WJ, Han YC. The sixth Nationwide Tuberculosis Prevalence Survey in Korea, 1990. Tuber Lung Dis 1993;74:323-31.

12. Bai GH, Park YK, Choi YW, Bai JI, Kim HJ, Chang CL, et al. Trend of anti-tuberculosis drug resistance in Korea, 19942004. Int J Tuberc Lung Dis 2007;11:571-6.

13. Kim J, Park YJ, Lee NY, Chang CL, Lee M, Shin JH. Anti-tuberculosis drug resistant rates in Mycobacterium tuberculosis Isolated from respiratory specimens: a multicenter study in Korea. Ann Clin Microbiol 2013;16:1-7.

14. Kim H, Mok JH, Kang B, Lee T, Lee HK, Jang HJ, et al. Trend of multidrug and fluoroquinolone resistance in Mycobacterium tuberculosis isolates from 2010 to 2014 in Korea: a multicenter study. Korean J Intern Med 2019;34:344-52. 
15. Mahmoudi A, Iseman MD. Pitfalls in the care of patients with tuberculosis: common errors and their association with the acquisition of drug resistance. JAMA 1993;270:65-8.

16. Espinal MA, Kim SJ, Suarez PG, Kam KM, Khomenko AG, Migliori GB, et al. Standard short-course chemotherapy for drugresistant tuberculosis: treatment outcomes in 6 countries. JAMA 2000;283:2537-45.

17. Menzies D, Benedetti A, Paydar A, Martin I, Royce S, Pai M, et al. Effect of duration and intermittency of rifampin on tuberculosis treatment outcomes: a systematic review and metaanalysis. PLoS Med 2009;6:e1000146.

18. Menzies D, Benedetti A, Paydar A, Royce S, Madhukar P, Burman W, et al. Standardized treatment of active tuberculosis in patients with previous treatment and/or with mono-resistance to isoniazid: a systematic review and meta-analysis. PLoS Med 2009;6:e1000150.

19. Mitchison DA, Nunn AJ. Influence of initial drug resistance on the response to short-course chemotherapy of pulmonary tuberculosis. Am Rev Respir Dis 1986;133:423-30.

20. Hong Kong Chest Service/British Medical Research Council. Five-year follow-up of a controlled trial of five 6-month regimens of chemotherapy for pulmonary tuberculosis. Am Rev Respir Dis 1987;136:1339-42.

21. Gegia M, Cohen T, Kalandadze I, Vashakidze L, Furin J. Outcomes among tuberculosis patients with isoniazid resistance in Georgia, 2007-2009. Int J Tuberc Lung Dis 2012;16:812-6.

22. Gegia M, Winters N, Benedetti A, van Soolingen D, Menzies D. Treatment of isoniazid-resistant tuberculosis with first-line drugs: a systematic review and meta-analysis. Lancet Infect Dis 2017;17:223-34.

23. Blumberg HM, Burman WJ, Chaisson RE, Daley CL, Etkind SC, Friedman LN, et al. American Thoracic Society/Centers for Disease Control and Prevention/Infectious Diseases Society of America: treatment of tuberculosis. Am J Respir Crit Care Med 2003;167:603-62.

24. World Health Organization. Companion handbook to the WHO guidelines for the programmatic management of drugresistant tuberculosis [Internet]. Geneva: World Health Organization; 2014 [cited 2019 Jun 1]. Available from: https:// www.who.int/tb/publications/pmdt_companionhandbook/ en/.

25. World Health Organization. Guidance for national tuberculosis programmes on the management of tuberculosis in children [Internet]. Geneva: World Health Organization; 2006 [cited 2019 Jun 1]. Available from: https://www.who.int/maternal_child_adolescent/documents/htm_tb_2006_371/en/.

26. World Health Organization. Guidelines for the programmatic management of drug-resistant tuberculosis (emergency update 2008) [Internet]. Geneva: World Health Organization; 2008 [cited 2019 Jun 1]. Available from: https://apps.who.int/ iris/handle/10665/43965.

27. Escalante P, Graviss EA, Griffith DE, Musser JM, Awe RJ. Treatment of isoniazid-resistant tuberculosis in southeastern
Texas. Chest 2001;119:1730-6.

28. Kim YH, Suh GY, Chung MP, Kim H, Kwon OJ, Lim SY, et al. Treatment of isoniazid-resistant pulmonary tuberculosis. BMC Infect Dis 2008;8:6.

29. Cattamanchi A, Dantes RB, Metcalfe JZ, Jarlsberg LG, Grinsdale J, Kawamura LM, et al. Clinical characteristics and treatment outcomes of patients with isoniazid-monoresistant tuberculosis. Clin Infect Dis 2009;48:179-85.

30. Bang D, Andersen PH, Andersen AB, Thomsen VO. Isoniazidresistant tuberculosis in Denmark: mutations, transmission and treatment outcome. J Infect 2010;60:452-7.

31. Munang ML, Kariuki M, Dedicoat M. Isoniazid-resistant tuberculosis in Birmingham, United Kingdom, 1999-2010. QJM 2015;108:19-25.

32. Romanowski K, Chiang LY, Roth DZ, Krajden M, Tang P, Cook VJ, et al. Treatment outcomes for isoniazid-resistant tuberculosis under program conditions in British Columbia, Canada. BMC Infect Dis 2017;17:604.

33. Stagg HR, Harris RJ, Hatherell HA, Obach D, Zhao H, Tsuchiya $\mathrm{N}$, et al. What are the most efficacious treatment regimens for isoniazid-resistant tuberculosis? A systematic review and network meta-analysis. Thorax 2016;71:940-9.

34. Stagg HR, Lipman MC, McHugh TD, Jenkins HE. Isoniazidresistant tuberculosis: a cause for concern? Int J Tuberc Lung Dis 2017;21:129-39.

35. Stagg HR, Bothamley GH, Davidson JA, Kunst H, Lalor MK, Lipman MC, et al. Fluoroquinolones and isoniazid-resistant tuberculosis: implications for the 2018 WHO guidance. Eur Respir J 2019;54:1900982.

36. Fregonese F, Ahuja SD, Akkerman OW, Arakaki-Sanchez D, Ayakaka I, Baghaei P, et al. Comparison of different treatments for isoniazid-resistant tuberculosis: an individual patient data meta-analysis. Lancet Respir Med 2018;6:265-75.

37. World Health Organization. WHO consolidated guidelines on drug-resistant tuberculosis treatment [Internet]. Geneva: World Health Organization; 2019 [cited 2019 Jun 1]. Available from: https://www.who.int/tb/publications/2019/consolidated-guidelines-drug-resistant-TB-treatment/en/.

38. Stewart SM, Crofton JW. The clinical significance of low degrees of drug resistance in pulmonary tuberculosis. Am Rev Respir Dis 1964;89:811-29.

39. World Health Organization. WHO treatment guidelines for isoniazid-resistant tuberculosis: supplement to the WHO treatment guidelines for drug-resistant tuberculosis [Internet]. Geneva: World Health Organization; 2018 [cited 2019 Jun 1]. Available from: https://www.who.int/tb/publications/2018/ WHO_guidelines_isoniazid_resistant_TB/en/.

40. Zhang Y, Heym B, Allen B, Young D, Cole S. The catalaseperoxidase gene and isoniazid resistance of Mycobacterium tuberculosis. Nature 1992;358:591-3.

41. Piatek AS, Telenti A, Murray MR, El-Hajj H, Jacobs WR Jr, Kramer FR, et al. Genotypic analysis of Mycobacterium tuberculosis in two distinct populations using molecular bea- 
cons: implications for rapid susceptibility testing. Antimicrob Agents Chemother 2000;44:103-10.

42. Ramaswamy SV, Reich R, Dou SJ, Jasperse L, Pan X, Wanger A, et al. Single nucleotide polymorphisms in genes associated with isoniazid resistance in Mycobacterium tuberculosis. Antimicrob Agents Chemother 2003;47:1241-50.

43. Ramaswamy S, Musser JM. Molecular genetic basis of antimicrobial agent resistance in Mycobacterium tuberculosis: 1998 update. Tuber Lung Dis 1998;79:3-29.

44. Dalla Costa ER, Ribeiro MO, Silva MS, Arnold LS, Rostirolla DC, Cafrune PI, et al. Correlations of mutations in katG, oxyRahpC and inhA genes and in vitro susceptibility in Mycobacterium tuberculosis clinical strains segregated by spoligotype families from tuberculosis prevalent countries in South America. BMC Microbiol 2009;9:39.

45. Banerjee A, Dubnau E, Quemard A, Balasubramanian V, Um KS, Wilson T, et al. inhA, a gene encoding a target for isoniazid and ethionamide in Mycobacterium tuberculosis. Science 1994;263:227-30.

46. Canetti G. Present aspects of bacterial resistance in tuberculosis. Am Rev Respir Dis 1965;92:687-703.

47. Mitchison DA. How drug resistance emerges as a result of poor compliance during short course chemotherapy for tuberculosis. Int J Tuberc Lung Dis 1998;2:10-5.

48. Patel KB, Belmonte R, Crowe HM. Drug malabsorption and resistant tuberculosis in HIV-infected patients. N Engl J Med 1995;332:336-7.

49. Moore M, Onorato IM, McCray E, Castro KG. Trends in drugresistant tuberculosis in the United States, 1993-1996. JAMA 1997;278:833-7.

50. Forssbohm M, Loddenkemper R, Rieder HL. Isoniazid resistance among tuberculosis patients by birth cohort in Germany. Int J Tuberc Lung Dis 2003;7:973-9.

51. Fox L, Kramer MR, Haim I, Priess R, Metvachuk A, Shitrit D. Comparison of isoniazid monoresistant tuberculosis with drug-susceptible tuberculosis and multidrug-resistant tuberculosis. Eur J Clin Microbiol Infect Dis 2011;30:863-7.

52. Bass JB Jr, Farer LS, Hopewell PC, O’Brien R, Jacobs RF, Ruben F, et al. Treatment of tuberculosis and tuberculosis infection in adults and children. American Thoracic Society and The Centers for Disease Control and Prevention. Am J Respir Crit Care Med 1994;149:1359-74.

53. Chemotherapy and management of tuberculosis in the United Kingdom: recommendations 1998. Joint Tuberculosis Committee of the British Thoracic Society. Thorax 1998;53:536-48.

54. National Collaborating Centre for Chronic Conditions; Centre for Clinical Practice at NICE. Tuberculosis: clinical diagnosis and management of tuberculosis, and measures for its prevention and control. London: National Institute for Health and Clinical Excellence; 2011.

55. National Institute for Health and Care Excellence. Tuberculosis: NICE guideline (NG33) [Internet]. London: National
Institute for Health and Care Excellence; 2016 [cited 2019 Jun 1]. Available from: https://www.nice.org.uk/guidance/ng33.

56. Tam CM, Chan SL, Lam CW, Leung CC, Kam KM, Morris JS, et al. Rifapentine and isoniazid in the continuation phase of treating pulmonary tuberculosis. Initial report. Am J Respir Crit Care Med 1998;157(6 pt 1):1726-33.

57. Bai KJ, Yu MC, Suo J, Chiang CY, Chiang IH, Lin TP, et al. Short-course chemotherapy for isoniazid-resistant pulmonary tuberculosis. J Formos Med Assoc 1998;97:278-82.

58. Babu Swai O, Aluoch JA, Githui WA, Thiong'o R, Edwards EA, Darbyshire JH, et al. Controlled clinical trial of a regimen of two durations for the treatment of isoniazid resistant pulmonary tuberculosis. Tubercle 1988;69:5-14.

59. Ormerod LP, Horsfield N, Green RM. Can a nine-month regimen be used to treat isoniazid resistant tuberculosis diagnosed after standard treatment is started? J Infect 2001;42:13.

60. Nolan CM, Goldberg SV. Treatment of isoniazid-resistant tuberculosis with isoniazid, rifampin, ethambutol, and pyrazinamide for 6 months. Int J Tuberc Lung Dis 2002;6:952-8.

61. A controlled clinical trial of oral short-course regimens in the treatment of sputum-positive pulmonary tuberculosis. Tuberculosis Research Centre. Int J Tuberc Lung Dis 1997;1:509-17.

62. Seung KJ, Gelmanova IE, Peremitin GG, Golubchikova VT, Pavlova VE, Sirotkina OB, et al. The effect of initial drug resistance on treatment response and acquired drug resistance during standardized short-course chemotherapy for tuberculosis. Clin Infect Dis 2004;39:1321-8.

63. Wang TY, Lin SM, Shie SS, Chou PC, Huang CD, Chung FT, et al. Clinical characteristics and treatment outcomes of patients with low- and high-concentration isoniazid-monoresistant tuberculosis. PLoS One 2014;9:e86316.

64. Baez-Saldana R, Delgado-Sanchez G, Garcia-Garcia L, CruzHervert LP, Montesinos-Castillo M, Ferreyra-Reyes L, et al. Isoniazid mono-resistant tuberculosis: impact on treatment outcome and survival of pulmonary tuberculosis patients in Southern Mexico 1995-2010. PLoS One 2016;11:e0168955.

65. Deepa D, Achanta S, Jaju J, Rao K, Samyukta R, Claassens M, et al. The impact of isoniazid resistance on the treatment outcomes of smear positive re-treatment tuberculosis patients in the state of Andhra Pradesh, India. PLoS One 2013;8:e76189.

66. Koh WJ, Kwon OJ, Park YK, Lew WJ, Bai GH. Development of multidrug resistance during treatment of isoniazid-resistant tuberculosis. Eur Respir J 2005;26:557.

67. Low rate of emergence of drug resistance in sputum positive patients treated with short course chemotherapy. Int J Tuberc Lung Dis 2001;5:40-5.

68. Jacobson KR, Theron D, Victor TC, Streicher EM, Warren RM, Murray MB. Treatment outcomes of isoniazid-resistant tuberculosis patients, Western Cape Province, South Africa. Clin Infect Dis 2011;53:369-72.

69. Lee H, Jeong BH, Park HY, Jeon K, Huh HJ, Lee NY, et al. Treatment outcomes with fluoroquinolone-containing regimens 
for isoniazid-resistant pulmonary tuberculosis. Antimicrob Agents Chemother 2016;60:471-7.

70. Chien JY, Chen YT, Wu SG, Lee JJ, Wang JY, Yu CJ. Treatment outcome of patients with isoniazid mono-resistant tuberculosis. Clin Microbiol Infect 2015;21:59-68.

71. Villegas L, Otero L, Sterling TR, Huaman MA, Van der Stuyft P, Gotuzzo E, et al. Prevalence, risk factors, and treatment outcomes of isoniazid- and rifampicin-mono-resistant pulmonary tuberculosis in Lima, Peru. PLoS One 2016;11:e0152933.

72. Cornejo Garcia JG, Alarcon Guizado VA, Mendoza Ticona A, Alarcon E, Heldal E, Moore DA. Treatment outcomes for isoniazid-monoresistant tuberculosis in Peru, 2012-2014. PLoS One 2018;13:e0206658.

73. Public Health Agency of Canada. Canadian Tuberculosis Standards. 7th Edition. Chapter 8: Drug-resistant tuberculosis [Internet]. Ottawa: Public Health Agency of Canada; 2014 [cited 2019 Jun 1]. Available from: https://www.canada.ca/ en/public-health/services/infectious-diseases/canadiantuberculosis-standards-7th-edition.html.

74. Dorman SE, Johnson JL, Goldberg S, Muzanye G, Padayatchi
N, Bozeman L, et al. Substitution of moxifloxacin for isoniazid during intensive phase treatment of pulmonary tuberculosis. Am J Respir Crit Care Med 2009;180:273-80.

75. Ramachandran G, Hemanth Kumar AK, Srinivasan R, Geetharani A, Sugirda P, Nandhakumar B, et al. Effect of rifampicin \& isoniazid on the steady state pharmacokinetics of moxifloxacin. Indian J Med Res 2012;136:979-84.

76. Fish DN, Chow AT. The clinical pharmacokinetics of levofloxacin. Clin Pharmacokinet 1997;32:101-19.

77. Centers for Disease Control and Prevention (CDC). Update: Fatal and severe liver injuries associated with rifampin and pyrazinamide for latent tuberculosis infection, and revisions in American Thoracic Society/CDC recommendations: United States, 2001. MMWR Morb Mortal Wkly Rep 2001;50:7335 .

78. Lempens P, Meehan CJ, Vandelannoote K, Fissette K, de Rijk P, Van Deun A, et al. Isoniazid resistance levels of Mycobacterium tuberculosis can largely be predicted by high-confidence resistance-conferring mutations. Sci Rep 2018;8:3246. 